\title{
CLINICAL CHARACTERISTICS AND DETERMINANTS OF MACULAR CHANGES IN RETINITIS PIGMENTOSA IN UPPER EGYPT
}

\author{
Amer, A. \\ Ophthalmology dept., Faculty of Medicine, South Valley Univ., Qena, Egypt \\ E-mail: ahmedali.ophth@gmail.com
}

\begin{abstract}
Aim: to explore the clinical characteristics and macular changes of RP in a sample of Upper Egyptian population. Settings and design: descriptive cross-sectional study was conducted at a university hospital from January 2018 until May 2021. Subjects and Methods: The study included 178 patients with RP. From the patient notes, baseline data was collected including; age, sex, complaint, age of onset, family history and history of medical diseases such as deafness, neurological disorder. The collected data included best corrected visual acuity BCVA, intraocular pressure IOP, corneal topography, and fundus examination by both direct and indirect ophthalmoscopy. Findings of perimetry and macular examination by a spectral domain optical coherence tomography device were also collected. Results: Out of the 178 patients diagnosed with RP and included in the current study; about $53 \%(n=95)$ were males and $47 \%(n=83)$ were females. The mean age was $28.5 \pm 12.3$ years. BCVA was found better than 6112 in $15(8.4 \%)$ patients and worse than 1160 in 35 (19.7\%) patients. Emmetropic refraction (within $0.75 \mathrm{D}$ ) was found in 45 (25.3\%) patients, myopic refraction was found in 75 (42.1\%) patients. OCT findings included, retinal thinning which was found in $73(41 \%)$, epiretinal membranes in $8(4.5 \%)$, cystoid spaces in 15 (8.4\%) and normal macula in $45(25.3 \%)$ patients. Conclusion: RP has significant visual disabling effect on Upper Egyptian patients. Screening programs of the affected families should be adopted for early visual rehabilitation
\end{abstract}

Keywords: Retinitis pigmentosa, OCT changes, Systemic association

\section{Introduction}

Retinitis pigmentosa (RP) was first described and named after Donders in 1857 [1]. It is an inherited retinal dystrophy characterized by progressive degeneration of photoreceptors [2]. This is misnomer as it is actually not an inflammation but a genetic disorder affecting the photoreceptors mainly the rods. Historically, RP patients were believed to suffer from retinal inflammation in conjunction with the observed retinal pigmentary changes [1]. The prevalence of RP was generally considered to be about 1 in 4000 . Its prevalence is still underestimated in some populations [3]. For that it was reported as one of the most common etiologies of visual disability in all age groups [4]. Clinical diagnosis of RP depends on the presence of nyctalopia, 
family history, characteristic retinal pigmentary changes i.e. perivascular mid peripheral bone spicule pigmentation in addition to reduction of the electroretinogram (ERG) [5]. Gene diagnosis will have a place soon in the diagnosis and expected to be an affordable routine clinical test with the wide use of next-generation sequencing [3]. Sometimes RP develops in association with systemic diseases i.e. syndromic presentation e.g. Usher syndrome, Kearns-Sayre syndrome, Bardet-Biedl and Laurence-Moon syndromes [6]. Also, RP patient may have other ocular diseases e.g. posterior subcapsular cataract, cystoid macular edema and myopic refraction with or without keratoconus corneal changes [6]. Regarding

\section{Subjects and Methods}

This descriptive cross-sectional study was conducted at a university hospital from January 2018 until May 2021. It was conducted in the outpatient clinic of the Department of Ophthalmology, South Valley University Hospital, Qena, Egypt. The study included 178 patients with RP. From the patient notes, baseline data was collected including; age, sex, complaint, age of onset, family history, parents' consanguinity, and history of medical diseases such as deafness, neurological disorder, hormonal disturbance, and musculoskeletal disorders. Each patient's record was revised regarding the best corrected visual acuity using a Landolt chart, intraocular pressure using a Goldman applanation tonometer, slit lamp examination of the anterior segment, color vision testing using Ishihara chart, eye motility testing, corneal topography,

\section{Statistical Analysis}

Data was verified and analyzed using IBM-SPSS 23 (Statistical Package for Social Science, version 21; SPSS Inc., Armonk, NY). Descriptive statistics, including; means, standard deviations, medians, retinitis pigmentosa in Egypt, there are some studies [7-9]. Mebed, R., et al [7] studied the mutations in the rhodopsin gene (RHO) among Egyptian RP patients and detection of the different inheritance patterns of those patients. El Byoumi, et al [8] studied the use of low vision aid in Egyptian children with various visual disabilities including retinitis pigmentosa. Mahmoud Et al [9] measured the subfoveal choroidal thickness and outer retinal layer thickness in Retinitis Pigmentosa patients and correlate them with visual acuity. The current study aimed to explore the clinical characteristics and macular changes of $\mathrm{RP}$ in a sample of Upper Egyptian population.

and fundus examination by both direct and indirect ophthalmoscopy. Findings of the perimetry macular examination by a spectral domain optical coherence tomography device (RTVue; Optovue, Inc., Fremont, CA) were revised to detect the RP diagnostic triad (waxy pale optic disc, attenuated retinal arterioles and the perivascular bony spicules like pigmentation). Patients were excluded if they had previous pan-retinal photocoagulation (PRP), old retinal vein occlusion or retinal detachment (RD). Informed consent was obtained from all participants confirming that their clinical data would be used for research purposes only. The study obtained ethics approval from the ethics committee of Qena Faculty of Medicine at South Valley Univ. The study was conducted in accordance with the tenets of the Declaration of Helsinki.

ranges, and percentages, were calculated. Test of significances: Chi square was used to compare the difference in distribution of frequencies among different groups. For continuous variables independent sample 
t-test was carried out to compare the means between groups. Multivariable logistic regression analysis was calculated to investigate the independent significant

\section{Results}

Out of the 178 patients diagnosed with RP and included in the current study; about $53 \%(n=95)$ were males and $47 \%(\mathrm{n}=83)$ were females. The mean age was $28.5 \pm 12.3$ years. Eighty-six (48.3\%) of patients complained of diminution of vision worse at night, $78(43.8 \%)$ patients complained of field defect, 32 (18\%) discovered accidently during routine fundus examination, tab. (1). Regarding onset of the symptoms $98(67.1 \%)$ patients reported that the condition started before age of twenty. Ninety-eight $(55 \%)$ of patients had positive family history of retinitis pigmentosa. One hundred-fifteen $(65 \%)$ of patients had positive parents' consanguinity. Regarding associated systemic disorders, 26 patients (14.6\%) had associated deafness i.e., Usher syndrome, 8 patients $(4.5 \%)$ had musculoskeletal disability, 5 (2.8\%) patients had mental retardation. Otherwise $(78.1 \%)$ patients had no associated systemic disorders, tab. (1). Best corrected visual acuity in the better eye was found better than $6 \backslash 12$ in $15(8.4 \%)$ patients, between $6 \backslash 60$ and $6 \backslash 12$ in $37(20.8 \%)$ patients, between $6 \backslash 60$ and $3 \backslash 60$ in $39(21.9 \%)$ patients, between $3 \backslash 60$ and $1 \backslash 60$ in 52 (29.2\%) patients, worse than $1 \backslash 60$ in 35 $(19.7 \%)$ patients. Regarding the refraction, emmetropic refraction (within $0.75 \mathrm{D}$ ) was found in 45 (25.3\%) patients, myopic refraction was found in $75(42.1 \%)$ patients, astigmatic refraction was found in 37 (20.8\%) patients and hyperopic refraction was found in $21(11.8 \%)$ patients, tab. (2). Regarding intraocular pressure was found high (more than $21 \mathrm{mmHg}$ ) in 15 $(8.5 \%)$ patients who had open anterior chamber angle and glaucomatous cupping. Posterior subcapsular cataract was found predictors of viability (Odds Ratio -OR-, $95 \%$ confidence interval $-95 \%$ CI-). A Pvalue $<0.05$ was considered significant.

in $53(29.8 \%)$ patients. Defective ocular motility in the form of total ophthalmoplegia was found in $3(1.7 \%)$ patients, concomitant exotropia was found in $8(4.5 \%)$ patients, concomitant esotropia was found in $5(2.8 \%)$ patients, tab. (2). Revising the corneal topography of 60 patients only, there were keratoconic features in $5(2.8 \%)$ patients. OCT Macular findings were available for only 156 patients. Retinal thinning was found in $73(41 \%)$, epiretinal membranes in $8(4.5 \%)$, cystoid spaces in $15(8.4 \%)$ and normal macula in $45(25.3 \%)$ patients. Perimetry findings were available for 95 patients, $65(36.5 \%)$ patients showed field contraction, $9(5.1 \%)$ patients showed arcuate scotomata, $5(2.8 \%)$ patients showed paracentral scotoma, normal visual field was found in $4(2.2 \%)$ patients and 12 (6.7\%) showed insignificant changes on visual filed, tab. (2). There was statistically significant negative moderate correlation between age of patient/age at onset of symptoms and the BCVA ( $\mathrm{r}=-0.197$ and $-0.275, p=0.004$ and 0.001 , respectively). In other words, with increase in the patients age/age at onset there was decrease in the BCVA, tab. (1). Tables ( $3 \& 4$ ) showed the predictor of macular/ocular defect among RP cases. The final multivariable model contained five predictors (patient's age and sex, family history and consanguinity and BCVA). For age, with one-year increase there was $4.3 \%$ decrease in the risk of macular defect (OR: 0.957, 95\% CI: 1.01-1.02, $\mathrm{p}=0.047$ ). Also, female RP patients had 3.5 times more risk of having macular defect compared with males. (OR: 3.513, 95\% CI: 1.12-9.02, $\mathrm{p}=0.031$ ). Moreover, the probability of macular defect in RP cases with positive family history and consanguinity was 8.8 
and 6 times (OR: 8.769 and 6.024, 95\% CI: 2.82-17.27 and 1.945-12.66, p<0.001 and 0.002 , respectively). Likewise, with one-point increase in the BCVA (LogMAR,
BCVA), there was 2.9 times increase in the likelihood of having macular defect (OR: 2.857, 95\% CI: 1.03-5.18, p=0.044).

Table 1: Baseline characteristics of the studied sample

\begin{tabular}{|c|c|c|}
\hline Variable & Category & $n=178$ \\
\hline \multirow{2}{*}{ Age in years } & - Mean \pm SD & $27.28 \pm 10.9$ \\
\hline & - Median (Range) & $27(7-59)$ \\
\hline \multirow{2}{*}{ Sex } & - Male & $95(53.4 \%)$ \\
\hline & - Female & $83(46.6 \%)$ \\
\hline \multirow{3}{*}{ Complaint } & - Night diminution of vision & $81(45.5 \%)$ \\
\hline & - Field defects & $67(37.6 \%)$ \\
\hline & - Accidentally discovered & $30(16.9 \%)$ \\
\hline \multirow{3}{*}{$\begin{array}{l}\text { Age of Symptom Onset } \\
(n=148)\end{array}$} & - Mean \pm SD & $21.42 \pm 8.5$ \\
\hline & - Median (Range) & $19(7-42)$ \\
\hline & - Onset before 20 years & $86(58.1 \%)$ \\
\hline Family History & - Positive & $97(54.5 \%)$ \\
\hline Parents' Consanguinity & - Positive & $115(65 \%)$ \\
\hline \multirow{4}{*}{ Comorbidity } & - No & $139(78.1 \%)$ \\
\hline & - Usher syndrome & $26(14.6 \%)$ \\
\hline & - Musculoskeletal disorder & $8(4.5 \%)$ \\
\hline & - Mental retardation & $5(2.8 \%)$ \\
\hline
\end{tabular}

Table 2: Ocular Findings of the studied sample

\begin{tabular}{|c|c|c|}
\hline Variable & Category & $\mathrm{n}=178$ \\
\hline \multirow{2}{*}{ Age in years } & - Mean \pm SD & $27.28 \pm 10.9$ \\
\hline & - Median (Range) & $27(7-59)$ \\
\hline \multirow[t]{2}{*}{ Sex } & - Male & $95(53.4 \%)$ \\
\hline & - Female & $83(46.6 \%)$ \\
\hline \multirow[t]{3}{*}{ Complaint } & - Night diminution of vision & $81(45.5 \%)$ \\
\hline & - Field defects & $67(37.6 \%)$ \\
\hline & - Accidentally discovered & $30(16.9 \%)$ \\
\hline \multirow{3}{*}{$\begin{array}{l}\text { Age of Symptom Onset } \\
(n=148)\end{array}$} & - Mean \pm SD & $21.42 \pm 8.5$ \\
\hline & - Median (Range) & $19(7-42)$ \\
\hline & - Onset before 20 years & $86(58.1 \%)$ \\
\hline Family History & - Positive & $97(54.5 \%)$ \\
\hline Parents' Consanguinity & - Positive & $115(65 \%)$ \\
\hline \multirow[t]{4}{*}{ Comorbidity } & - No & $139(78.1 \%)$ \\
\hline & - Usher syndrome & $26(14.6 \%)$ \\
\hline & - Musculoskeletal disorder & $8(4.5 \%)$ \\
\hline & - Mental retardation & $5(2.8 \%)$ \\
\hline
\end{tabular}

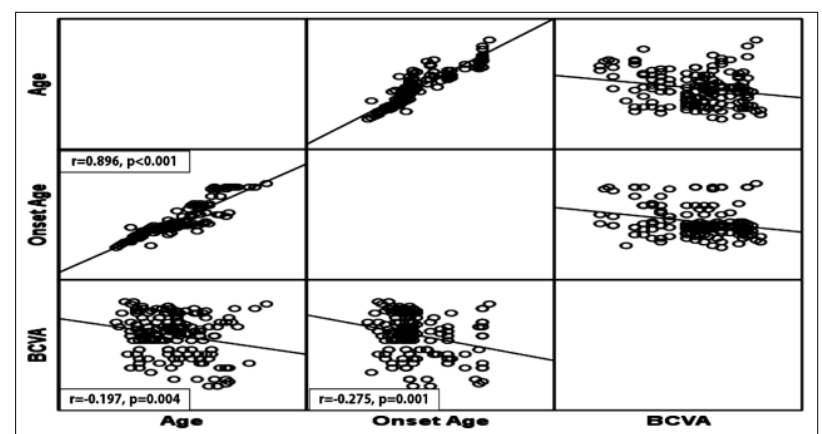

Figure 1: Univariate correlation between patient's age/age of onset and BCVA 
Table 3: Determinants of Macular changes with retinitis pigmentosa

\begin{tabular}{|c|c|c|c|c|}
\hline$--\cdot-\cdot$ & - & $\begin{array}{c}\text { No Defect } \\
(\mathrm{n}=\mathbf{3 4})\end{array}$ & $\begin{array}{c}\text { Defect } \\
(n=144)\end{array}$ & P-value \\
\hline Age/years & - Mean $\pm \mathrm{SD}$ & $32.29 \pm 5.1$ & $26.10 \pm 3.8$ & $=0.003 *$ \\
\hline Age at Onset/years & - Mean \pm SD & $24.56 \pm 4.5$ & $20.38 \pm 2.9$ & $=0.020 *$ \\
\hline \multirow{2}{*}{ Sex } & - Male & $25(73.5 \%)$ & $70(48.6 \%)$ & \multirow{2}{*}{$=0.009 * *$} \\
\hline & - Female & $9(26.5 \%)$ & $74(51.4 \%)$ & \\
\hline \multirow{3}{*}{ Complaint } & - Night VD & $19(55.9 \%)$ & $62(43 \%)$ & \multirow{3}{*}{$=0.157 * *$} \\
\hline & - Field defects & $8(23.5 \%)$ & $59(41 \%)$ & \\
\hline & - Accidental & $7(20.6 \%)$ & $23(16 \%)$ & \\
\hline Family History & - Positive & $14(41.2 \%)$ & $101(70.1 \%)$ & $=0.001 * *$ \\
\hline Consanguinity & - Positive & $9(26.5 \%)$ & $88(61.1 \%)$ & $<0.001 * *$ \\
\hline Comorbidity & - Yes & $2(5.9 \%)$ & $37(25.7 \%)$ & $=0.012 * *$ \\
\hline BCVA & - Mean \pm SD & $0.83 \pm 0.1$ & $1.28 \pm 0.03$ & $<0.001 *$ \\
\hline \multirow{4}{*}{ Refraction State } & - Emmetropia & $9(26.5 \%)$ & $36(25 \%)$ & \multirow{4}{*}{$=0.020 * *$} \\
\hline & - Myopia & $17(50 \%)$ & $58(40.3 \%)$ & \\
\hline & - Hyperopia & $7(20.6 \%)$ & $14(9.7 \%)$ & \\
\hline & - Astigmatism & $1(2.9 \%)$ & $36(25 \%)$ & \\
\hline
\end{tabular}

*Independent t-test was used to compare differences in means between groups.

**Chi-square test was used to compare differences in frequency between groups.

Table 4: Predictors of macular changes associated with retinitis pigmentosa: Logistic Regression Model

\begin{tabular}{|c|c|c|c|c|}
\hline \multirow{2}{*}{ Variable } & \multicolumn{2}{|l|}{ Bivariate } & \multicolumn{2}{|c|}{ Multivariable } \\
\hline & OR $(95 \%$ CI $)$ & P-value & OR $(95 \%$ CI $)$ & P-value \\
\hline Age/years & $0.949(0.916-0.983)$ & $=0.004$ & $0.957(1.002-1.015)$ & $=0.047$ \\
\hline Age at Onset/years & $0.948(0.906-0.993)$ & $=0.024$ & & \\
\hline Sex (Female) & $2.937(1.282-6.728)$ & $=0.011$ & $3.513(1.119-9.022)$ & $=0.031$ \\
\hline Family History & $4.365(1.899-8.014)$ & $=0.001$ & $8.769(2.820-17.27)$ & $<0.001$ \\
\hline Consanguinity & $3.355(1.553-7.251)$ & $=0.002$ & $6.024(1.945-12.66)$ & $=0.002$ \\
\hline Comorbidity & $5.533(1.264-18.242)$ & $=0.023$ & & \\
\hline BCVA & $6.181(2.766-9.812)$ & $<0.001$ & $2.857(1.027-5.184)$ & $=0.044$ \\
\hline \multicolumn{5}{|l|}{ Refraction State } \\
\hline - Emmetropia & 1 & $<0.001$ & -- & -- \\
\hline - Myopia & $0.853(0.344-2.116)$ & $=0.732$ & -- & -- \\
\hline - Hyperopia & $0.500(0.156-1.603)$ & $=0.243$ & -- & -- \\
\hline - Astigmatism & $9.012(1.084-25.756)$ & $=0.042$ & -- & -- \\
\hline
\end{tabular}

\section{Discussion}

The mean age of patients in the present study was $27.28 \pm 10.9$ years i.e. in young people this is lower than average age of Japanese patients [10] and American patients [11]. However, in the current study, oneyear increase in the age of the patient was associated with $4.3 \%$ decrease in the risk of having macular defect. From the results of the current study, males were more affected than females and this was consistent with the findings of studies on American population [11,12] and opposite to what was found in Japanese study [10] where females were more affected $(52 \%)$ than males. In the present study, female RP patients had 3.5 times more risk of 
having macular defect compared with males. The main compliant of RP in the studied Upper Egyptian cohort was night blindness $(46 \%)$ followed by field defect $(38 \%)$. This was in agreement with a meta-anlysis on RP in the USA [4]. The onset of RP in the current study was before the age of 20 years which was younger than what was found in Japanese study where age of diagnosis was 35.1 years [10]. This difference may be attributed to the variation in the definition of the disease onset between the two studies i.e. in the current study the age of onset was defined as the onset of the patients' symptoms from the patient history while in the Japanese one, it was defined as the time in which the patient was diagnosed with RP. Another study [13] reported that the age of onset vary from infancy to late middle age. About $55 \%$ of the studied cohort had positive family history of the disease and this was higher than what was reported in the USA $(40.1 \%)$ [14]. This could be attributed to the unawareness of some patients about the nature of the disease, so that they might consider any retinal disease in the family as RP. Additionally, no authentic clinical documents were available about other affected family members. Also, the majority of patients recruited for the present study had positive parents' consanguinity. Regarding the syndromic RP, Usher syndrome was found in about $15 \%$ of all cases which was slightly lower than another Japanese study $(23.8 \%)$ [15] and slightly higher (12\%) than a European study conducted in Denmark [16]. In the current study, mental retardation was found in less than $3 \%$ of the sample which was much lower than the Danish study (11\%) [16] such difference may be attributed to the wider range and larger sample included. Regarding BCVA, the present study found that less than $10 \%$ of RP patients had BCVA better than $6 / 12$ and this was in line with what was reported in a major American review of RP where $10 \%$ of RP patients had BCVA $6 \backslash 12$ or better [4]. Moreover, about $20 \%$ had vision less than 1/60 and an American study [14] reported about $12 \%$ of patients had vision hand motion or less. In the present study, with onepoint increase in the BCVA (LogMAR, BCVA), there was 2.9 times increase in the likelihood of having macular defect. Regarding refractive state of the eye, in the current study the majority of RP patients were myopic similar to the results of other studies [4, 6,14,17]. Regarding the association of cataract with RP, the present study showed that about $47 \%$ of patients had posterior subcapsular cataract and this was lower than a study in the USA [11] which reported that $53 \%$ of RP patients had cataract but the latter included 17 bilaterally aphakic patients. Likewise, several American studies reported this occurrence in $50 \%$ of the samples $[12,18]$. On the other hand, an African study in Nigeria [19] had much lower figure (20\%). In the present study, glaucoma was found in $8.5 \%$ of patients and all have open angle type. This was lower than that of the multicenter African study [19] $(11.5 \%)$ which reported that $15 \%$ of blindness in RP patients was due to glaucoma. However, a systematic review study [4] concluded that ocular tensions remain normal even in end stage of the disease. Respecting the associated keratoconus with RP, the current study found that less than $3 \%$ of cases had keratoconus features, and this was similar to other studies $[20,21]$ that reported fairly rare association between the two conditions. However, one study in Czech Republic [22] reported that 38\% of cases of retinal dystrophy developed keratoconus. For the macular OCT changes with RP, CME was found in $8.5 \%$ of patients and this was much lower than what was found in a Korean study where CME found in $(20.9 \%)$ of studied eyes [23]. However, the international reported prevalence of CME with RP varied from 11 to $49 \%$ [24-26]. ERM was found in about $5 \%$ while the reported figure varied from $15 \%$ [27,28] to $80 \%$ [29] in other studies. In the present study, the one- 
point increase in the BCVA (Log MAR, BCVA), there was 2.9 times increase in the likelihood of having macular defect. However, other studies [30,31] correlated between the decrease in BCVA and the absence of ELM, outer segment OS and RPE. Regarding the visual field changes with RP, this study found that field contraction was more common (37\%) and this was like what was reported by an American study [14] that found that $43 \%$ of patients had visual field limited to small central island. While an American study [32] reported that mid-peripheral scotomas that progressively enlarge over years with central areas of vision that later slowly disappear was associated with RP.

\section{Conclusion}

$R P$ has significant visual disabling effect on Upper Egyptian patients. Screening programs of the affected families should be adopted for early visual rehabilitation. Special care should be provided for those with positive family history.

\section{References}

1. Donders, F. Beiträge zur pathologischen Anatomie des Auges. Archiv für Ophthalmologie. 1857; 3 (1): 139-165.

2. Bunker, C., Berson, E., Bromley, W., et al. Prevalence of retinitis pigmentosa in Maine. Am. J. of Ophthalmology. 1984; 97 (3): 357-365.

3. Zhang, Q. Retinitis pigmentosa: Progress and perspective. The Asia-Pacific J. of Ophthalmology. 2016; 5 (4): 265271.

4. Pagon, R. Retinitis pigmentosa. Survey of Ophthalmology. 1988; 33(3): 137177.

5. Marmor, M., Arden, G., Nilsson, S., et al., Standard for clinical electroretinography (2004). Documenta Ophthalmologica. 2004; 108 (2): 107-114.

6. Natarajan, S., Retinitis pigmentosa: A brief overview. Indian J. of Ophthalmology. 2011; 59 (5): 343-346.

7. Mebed, R., Ali, Y., Soloumac, N., et al. Rhodopsin mutations are scarcely implicated in autosomal recessive retinitis pigmentosa: A preliminary study of Egyptian retinitis pigmentosa patients. Egyptian J. of Medical Human Genetics. 2015; 16 (4): 355-359.

8. El Byoumi, B. \& Mousa, A. Visual function of Egyptian children with low vision and the demographic determinants. Middle East African J. of Ophthalmology, 2010. 17 (1): 78.
9. Mahmoud, Y., Mahmoud, Y., Eliwa, T., Elmofty, H., et al., Subfoveal choroidal thickness measured by swept source OCT in retinitis pigmentosa patients. QJM: An Int. J. of Medicine, 2020; 113 (Sup.1): hcaa 058. 009.

10. Tsujikawa, M., Wada, Y., Sukegawa, M., et al., Age at onset curves of retinitis pigmentosa. Archives of Ophthalmology, 2008; 126(3): 337-340.

11. Fishman, G., Anderson, R. \& Lourenco, P. Prevalence of posterior subcapsular lens opacities in patients with retinitis pigmentosa. British J. of Ophthalmology. 1985; 69 (4): 263-266.

12. Fujiwara, K., Ikeda,Y., Murakami, Y., et al. Risk factors for posterior subcapsular cataract in retinitis pigmentosa. Invest Ophthalmol Vis Sci. 2017; 58 (5): 2534-2537.

13. Haim, M., Holm, N. \& Rosenberg, T. Prevalence of retinitis pigmentosa and allied disorders in Denmark: I. Main results. Acta Ophthalmologica, 1992; 70 (2): 178-186.

14. Pruett, R. Retinitis pigmentosa: Clinical observations and correlations. Transactions of the Am. Ophthalmological Society, 1983; 81: 693-735.

15. Boughman, J., Vernon, M. \& Shaver, K. Usher syndrome: definition and estimate of prevalence from two 
high-risk populations. J. of Chronic Diseases, 1983; 36 (8): 595-603.

16. Haim, M., Epidemiology of retinitis pigmentosa in Denmark. Acta Ophthalmologica Scandinavica. 2002; Sup., (233): 1-34.

17. Sieving, P. \& Fishman, G. Refractive errors of retinitis pigmentosa patients. British J. of Ophthalmology. 1978; 62 (3): 163-167.

18. Heckenlively, J. The frequency of posterior subcapsular cataract in the hereditary retinal degenerations. $\boldsymbol{A m}$. J. of Ophthalmology, 1982; 93 (6): 733-738.

19. Onakpoya, O., Adeoti, C., Oluleye, T., et al., Clinical presentation and visual status of retinitis pigmentosa patients: A multicenter study in southwestern Nigeria. Clin Ophthalmol., 2016; 10: 1579-1583.

20.Zemba, M., Zaharia, A. \& Dumitrescu O. Association of retinitis pigmentosa and advanced keratoconus in siblings. Rom J. Ophthalmol., 2020. 64 (3): 313321.

21. Kanski, J. \& Bowling, B. Hereditary fundus dystrophies. Kanski's Clinical Ophthalmology: A systematic approach. $8^{\text {th }}$ ed., Elsevier, Edinburgh, 2016.

22. Karel, I., Keratoconus in congenital diffuse tapetoretinal degeneration. $\boldsymbol{O p h}$ thalmologica. 1968; 155 (1): 8-15.

23. Kim, Y., Joe, S., Lee, D., et al., Correlations between spectral-domain OCT measurements and visual acuity in cystoid macular edema associated with retinitis pigmentosa. Investigative Ophthalmology \& Visual Science, 2013; 54 (2): 1303-1309.

24. Apushkin, M., Fishman, G. \& Janowicz, M. Monitoring cystoid macular edema by optical coherence tomography in patients with retinitis pigmentosa. Ophthalmology. 2004; 111(10): 1899-1904.

25. Hajali, M., Fishman, G. \& Anderson, $\mathrm{R}$. The prevalence of cystoid macular oedema in retinitis pigmentosa patients determined by optical coherence tomography. Br J. Ophthalmol. 2008; 92 (8): 1065-1068.

26. Hirakawa, H., Iijima, $H$ Gohdo, T., et al., Optical coherence tomography of cystoid macular edema associated with retinitis pigmentosa. Am $\boldsymbol{J}$. Ophthalmol. 1999; 128 (2): 185-91.

27. Lupo, S., Grenga, P. \& Vingolo, E. Fourier-domain optical coherence tomography and microperimetry findings in retinitis pigmentosa. Am. J. of $\boldsymbol{O} \boldsymbol{p h}$ thalmology. 2011; 151 (1) 106-111.

28. Hartong, D., Berson, E. \& Dryja, T. Retinitis pigmentosa. The Lancet. 2006; 368 (9549) 1795-1809.

29. Fragiotta, S., Rossi, T., Carnevale, C., et al., Vitreo-macular interface disorders in retinitis pigmentosa. Graefes Arch Clin Exp Ophthalmol, 2019; 257 (10): 2137-2146.

30. Parodi, M., La Spina, C., Triolo, G., et al., Correlation of SD-OCT findings and visual function in patients with retinitis pigmentosa. Graefe's Archive for Clinical and Experimental Ophthalmology. 2016; 254 (7) 1275-1279.

31. Sousa, K., Fernandes, T., Gentil, R., et al., Outer retinal layers as predictors of visual acuity in retinitis pigmentosa: a cross-sectional study. Graefe's Archive for Clinical and Experimental Ophthalmology. 2019; 257 (2): 265-271.

32. Milam, A., De Castro, E., Smith, J., et al. Concentric retinitis pigmentosa: clinicopathologic correlations. Exp Eye Res. 2001; 73 (4): 493-508. 